\title{
O brincar para o desenvolvimento do esquema corporal, orientaçáo espacial e temporal: análise de uma intervenção ${ }^{1}$
}

\author{
Sara Domiciano Franco de Campos $^{a}$, Mirela de Oliveira Figueiredo ${ }^{b}$, \\ Sheila Maria Mazer-Gonçalvesc, Elisandra dos Santos ${ }^{\mathrm{d}}$, Letícia Carrillo Maronesi ${ }^{\mathrm{a}}$ \\ aUniversidade Federal de São Carlos - UFSCar, São Carlos, SP, Brasil.

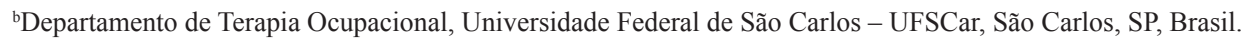 \\ 'Universidade de São Paulo - USP, Ribeirão Preto, SP, Brasil. \\ ${ }^{\mathrm{d} C e n t r o ~ U n i v e r s i t a ́ r i o ~ d e ~ A r a r a q u a r a ~-~ U N I A R A, ~ A r a r a q u a r a, ~ S P, ~ B r a s i l . ~}$
}

\begin{abstract}
Resumo: Introdução: A infância é uma fase significativa do desenvolvimento humano, na qual se desenvolvem várias aptidões, ocorrendo evoluções na aprendizagem. $\mathrm{O}$ ato de brincar é uma atividade do cotidiano das crianças e aperfeiçoa as habilidades cognitivas, sociais, emocionais e psicomotoras. Objetivo: Avaliar os resultados de uma intervenção para uma criança com atraso no desenvolvimento do esquema corporal, da orientação espacial e da orientação temporal. Método: Este estudo adotou o design quase-experimental do tipo pré e pós-teste. Foi aplicada a Escala de Desenvolvimento Motor (EDM) em uma criança de quatro anos. A partir dos resultados da EDM, foi elaborado um plano de intervenção com brincadeiras que estimulassem as aquisições acima citadas. A concretização do plano de intervenção teve duração de dois meses, sendo a criança avaliada antes e no término da intervenção. O Método Jacobson e Truax foi adotado para análise dos dados e verificação da ocorrência de mudanças confiáveis e clinicamente significativas. Resultados: A criança obteve mudança confiável nos três itens avaliados. Em relação à significância clínica, na organização espacial a criança mudou seu status clínico, passando para a população funcional. No esquema corporal, a criança permaneceu na população disfuncional, e na organização temporal apresentou-se na faixa de incerteza. Conclusão: Os resultados demonstraram mudanças positivas e confiáveis nos itens avaliados, confirmando um efeito positivo do brincar enquanto recurso terapêutico ocupacional presente no programa de intervenção elaborado. Ressalta-se a importância da realização de novos estudos com maior número de participantes para novos dados e descobertas sobre a utilização do brincar em intervenções no desenvolvimento de aquisições psicomotoras.
\end{abstract}

Palavras-chave: Terapia Ocupacional, Desenvolvimento Infantil, Brincadeiras.

\section{Play for the development of body schema and spatial and temporal orientation: analysis of an intervention}

\begin{abstract}
Introduction: Childhood is a significant stage in human development in which many skills are developed influencing learning progress. Play is an activity of children's daily lives that enhances cognitive, social, emotional, and psychomotor abilities. Objective: evaluate the results of an intervention for a child with delayed development of body schema and spatial and temporal orientation. Method: This study adopted the semi-experimental design type of pre and post-test. The Motor Development Scale (MDS) was applied in a four-year-old child. From the MDS results, an intervention plan was prepared concerning games that stimulate the previously mentioned
\end{abstract}

Autor para correspondência: Mirela de Oliveira Figueiredo, Departamento de Terapia Ocupacional, Universidade Federal de São Carlos, Rodovia Washington Luís, Km 235, SP-310, CEP 13565-905, São Carlos, SP, Brasil, e-mail: mirelafigueiredo@gmail.com

Recebido em Maio 24, 2016; $1^{\text {a }}$ Revisão em Ago. 9, 2016; 2 ${ }^{a}$ Revisão em Nov. 17, 2016; Aceito em Fev. 1, 2017. 
acquisitions. The implementation of the plan lasted two months and the child was evaluated before and at the end of the intervention. The JT method was adopted for data analysis and verification of significant and reliable clinical changes. Results: The child achieved significant change in the three items assessed. In terms of clinical significance, the child changed status on spatial organization, becoming part of the functional population. Body schema remained in the dysfunctional population and the child's temporal orientation was in the range of uncertainty. Conclusion: The results showed positive and reliable changes in the evaluated items, confirming the positive effect of play as an occupational therapeutic resource present in the developmental intervention program. It emphasizes the importance of conducting further studies with a larger number of participants for new data and findings on the use of play in interventions into psychomotor development.

Keywords: Occupational Therapy, Child Development, Play.

\section{Introdução}

O desenvolvimento psicomotor é um processo de alteração no nível de funcionamento do ser humano, sendo considerado um processo sequencial e contínuo, relacionado à idade cronológica, na qual os indivíduos adquirem uma enorme quantidade de habilidades que progridem de movimentos simples e desorganizados para altamente organizados e complexos (CAETANO; SILVEIRA; GOBBI, 2005; WILLRICH; AZEVEDO; FERNANDES, 2009). Dessa forma, o desenvolvimento psicomotor envolve o desenvolvimento funcional de todo o corpo e suas partes, sendo a base fundamental para o processo de aprendizagem da criança (HAYWOOD; GETCHELL, 2004; NICOLA, 2004; OLIVEIRA; SOUZA, 2013). Com isso, há uma estreita relação entre o que a criança é capaz de aprender cognitivamente, com o que é capaz de realizar motoramente (ROSA NETO et al., 2010).

Importante destacar que há padrôes fundamentais que regem o desenvolvimento, sendo que a fase que se estende do nascimento até aproximadamente os seis anos de idade corresponde ao período de aquisição, e após os seis anos, ao de refinamento e combinação dos padróes adquiridos (GALLAHUE; OZMUN; GOODWAY, 2013). Durante os primeiros seis anos de vida, para as aquisições dos padrões fundamentais, são necessários componentes psicomotores como o esquema corporal, a organização espacial e temporal (GALLAHUE, 2000; OLIVEIRA, 2002; PINTO, 2009; ROSA NETO et al., 2011).

O esquema corporal constitui-se pelo reconhecimento que se tem do próprio corpo por meio da conscientização do corpo, das funçôes de cada parte do corpo e das possibilidades de ação com o corpo e suas partes. Por isso, é resultado da captação e processamento de várias informaçôes obtidas pelos canais sensoriais, sendo sua construção advinda da organização das sensaçôes relativas ao próprio corpo em associação com dados do mundo exterior (ROSA NETO, 2002; ROSA NETO et al., 2011).

A organização espacial representa a orientação do indivíduo no espaço tendo como referência primeiro a si mesmo para posteriormente em relação aos objetos e/ou pessoas estáticos e em movimento. Todas as modalidades sensoriais participam na percepção espacial, e esta garante ao ser humano a evolução de comportamentos essenciais relativos à mobilidade, orientação e exploração (ROSA NETO, 2002; FONSECA; BELTRAME; TKAC, 2008).

A orientação temporal compõe-se pela capacidade do indivíduo em se situar em função da ocorrência (antes, durante, depois) e sucessão dos acontecimentos, da duração dos intervalos (noção de tempo longo/curto, ritmo regular/irregular, cadência rápida/lenta), da renovação cíclica dos períodos (dia, semana, meses, ano) e do caráter irreversível do tempo (impossibilidade de voltar no tempo). Está diretamente ligada à orientação espacial, sendo ambas indissociáveis, uma vez que o corpo coordena-se e movimenta-se continuamente dentro de um espaço determinado e em função do tempo (DE MEUR; STAES, 1991; VASCONSELLOS, 2002; FIGUEIREDO; EMMEL; ROSÁRIO, 2013).

Vários fatores podem influenciar e ser determinantes no desenvolvimento infantil, como as características pessoais e do meio ambiente físico e sociocultural em que a criança está inserida (FERNANDES; DANTAS; MOURÃO-CARVALHAL, 2014). Assim, as vivências do cotidiano relacionadas ao meio ambiente em que a criança está inserida propiciam experiências de amadurecimento durante o desenvolvimento. Essas experiências ajudam na construção da sua personalidade e no seu jeito de lidar com o mundo. Em virtude de o brincar constituir uma atividade que ocupa parte considerável do cotidiano da criança, este se torna fundamental para o desenvolvimento infantil (NUNES et al., 2013). 
Deste modo, o brincar e as brincadeiras contribuem para a estimulação do crescimento e desenvolvimento psíquico, relacional e geral da criança e podem fornecer informaçôes para o desempenho ocupacional (CASE-SMITH, 2005; CRUZ; EMMEL, 2007; NUNES et al., 2013), promovendo a transição de um estágio de desenvolvimento para outro (OLIVEIRA; FRANCISCHINI, 2009). Também influenciam na socialização da criança, proporcionando-lhe novas descobertas e aprendizados no contexto no qual está inserida.

Com isso, a brincadeira é uma atividade social e cultural e pressupóe um aprendizado. Para que esse aprendizado ocorra, a criança necessita experimentar alguma coisa para que tenha a habilidade de pensar sobre ela. A vantagem das aprendizagens alcançadas por meio do brincar está no fato de que os enganos cometidos não são considerados erros, mas tentativas de acerto. Quando a criança não tem medo de errar, arrisca mais e é mantido o clima de alegria e descontração, preservando assim o prazer na atividade que consequentemente contribuirá para o aprendizado (SCALHA et al., 2010).

A partir da compreensão do brincar enquanto uma ocupação que é fundamental na criança, a terapia ocupacional utiliza o brincar e as brincadeiras como recursos terapêuticos objetivando favorecer o desenvolvimento adequado das habilidades necessárias para cada faixa etária e o respectivo desempenho ocupacional da criança. Para isso, os terapeutas ocupacionais avaliam as brincadeiras e as atividades que as compóem, de forma que estas sejam adequadas para cada criança, de acordo com sua cultura, nível de desenvolvimento e necessidade (SIMON, 2001; CRUZ, 2002; GIARDINETTO et al., 2009). Além disso, por meio da utilização de brincadeiras, pelo terapeuta ocupacional, é possível proporcionar ações cuja importância se verifica não só no incremento dos componentes de desempenho, mas no fato de o brincar ser entendido como o principal papel ocupacional na infância, o qual deve ser estimulado e desenvolvido através de estratégias terapêuticas (GRIGOLATTO et al., 2008).

Por fim, considerando que o terapeuta ocupacional se constitui por um profissional capacitado para analisar e avaliar o brincar, planejar intervençôes e estimular as competências cognitivas, motoras e sociais da criança (KNOX, 2002; SOUZA; MARINO, 2013), o presente estudo teve por objetivo elaborar uma intervenção baseada em brincadeiras, para uma criança com atraso no desenvolvimento do esquema corporal, da orientação espacial e de orientação temporal, e avaliar a efetividade de seus resultados.

\section{Método}

A presente pesquisa utilizou o design metodológico de estudo quase-experimental do tipo pré e pós-teste. Neste tipo de design, o pesquisador realiza intervenção nas demandas que estão sendo investigadas. Os sujeitos de pesquisa que receberem a intervenção são formados considerando os critérios operacionais do estudo, para composição da amostra e recrutamento de voluntários (KENNY, 1975; SHANDISH, 2001).

\subsection{Caracterização da participante}

A participante, do sexo feminino, tinha quatro anos de idade e histórico de meningite, traumatismo cranioencefálico e hidrocefalia, pois quando bebê sofreu maus-tratos dos familiares. Atualmente não faz uso de válvula, está sob tutela de outra família e apresenta significativo atraso no desenvolvimento psicomotor. Frequenta uma associação de reabilitação infantil há quatro anos, com atendimentos semanais de fonoaudiologia e terapia ocupacional. Ressalta-se que uma das pesquisadoras do estudo era a terapeuta ocupacional da participante.

A seleção da participante seguiu os critérios de inclusão previamente estipulados: idade cronológica entre três e cinco anos e presença de atraso no desenvolvimento do esquema corporal, da orientação espacial e da orientação temporal com classificação em Nível Inferior para a idade cronológica, segundo a Escala de Desenvolvimento Motor (EMD) (ROSA NETO, 2002).

Os critérios para exclusão da participante relacionavam-se à presença de deficiência física, visual e/ou auditiva.

\subsection{Instrumento para coleta de dados}

A EDM de Rosa Neto (2002) compreende um conjunto de provas diversificadas e de dificuldade graduada, conduzindo a uma exploração minuciosa de diferentes setores do desenvolvimento, como motricidade fina, motricidade global, equilíbrio, esquema corporal, organização espacial, organizaçáo temporal e lateralidade. A aplicação em um sujeito permite avaliar seu nível de desenvolvimento psicomotor, considerando êxitos e fracassos, levando em conta as normas estabelecidas pelo instrumento.

\subsection{Procedimentos para coleta dos dados}

Esta pesquisa teve início mediante a aprovação do comitê de ética e garantiu-se durante toda a sua aplicação o cumprimento das exigências cabíveis. 
A instituição de reabilitação infantil no interior no estado de São Paulo, na qual a pesquisadora trabalha, foi selecionada para a coleta da amostra e autorizou a realizaçáo do estudo. Depois de selecionada a participante, foram explicados o objetivo e a forma de aplicação do estudo para a responsável, que assinou o termo de consentimento livre e esclarecido, autorizando a participação da filha.

O estudo foi desenvolvido na própria instituição nos períodos em que ocorreriam os seus atendimentos, de forma a não ter duplicidade de intervençóes e em virtude da indisponibilidade da criança em ir fora do horário institucional. Tanto os familiares quanto a instituição concordaram que este plano fosse o de atendimento terapêutico ocupacional no período.

A primeira etapa da coleta dos dados, denominada por pré-teste, se concretizou com a aplicação da EDM. Em seguida às avaliaçôes, foi realizada a fase de intervenção, com base na elaboração e aplicaçáo de um programa voltado a suprir as necessidades apontadas nos resultados da EDM. Após transcorridos 2 meses de intervenção, o desempenho da participante foi reavaliado por meio da EDM, analisando-se a ocorrência de mudanças confiáveis e estatisticamente significativas.

\subsection{Plano de intervenção}

O plano de intervenção, elaborado a partir dos resultados da EDM, foi composto por brincadeiras que estimulassem as aquisiçóes que se apresentaram em déficit, sendo estas o esquema corporal, a orientação espacial e a orientaçáo temporal.

Foram realizadas oito sessôes de intervenção, uma por semana, e cada sessáo teve duraçáo de trinta minutos. As brincadeiras realizadas são citadas a seguir e descritas na Tabela 1, de acordo com os seus objetivos, procedimentos e desempenho da criança: Circuito Psicomotor, Brincando com o corpo, Desenho do corpo humano, Colagem de objetos, Siga o mestre, Brincadeira da casinha, Reflexo no espelho, Reprodução de história, Pintura no espelho.

No total foram dez encontros, sendo um para avaliação, oito para as intervençóes e um para reavaliação. No final do estudo, depois de todos os resultados analisados, foi realizada uma devolutiva

Tabela 1. Descrição do desempenho da participante nas brincadeiras.

\begin{tabular}{|c|c|c|c|}
\hline Atendimento & Brincadeiras & Objetivos e Procedimentos & Desempenho \\
\hline \multirow[t]{2}{*}{ Primeiro } & $\begin{array}{c}\text { Circuito } \\
\text { Psicomotor }\end{array}$ & $\begin{array}{l}\text { Estimular a organização espacial e } \\
\text { temporal, e consistiu em obstáculos } \\
\text { formados com bambolê, cones e } \\
\text { corda, no qual a participante deveria } \\
\text { seguir uma sequência e realizar } \\
\text { um movimento diferente em cada } \\
\text { obstáculo, como pular com os dois } \\
\text { pés uma altura } 5 \mathrm{~cm} \text {, andar sem pisar } \\
\text { no bambolê, transpassar os cones, } \\
\text { pular com um pé só uma marcação } \\
\text { no chão. }\end{array}$ & \multirow{2}{*}{$\begin{array}{l}\text { Criança teve muita dificuldade no } \\
\text { circuito, mesmo com comandos } \\
\text { verbais e dicas visuais. Não } \\
\text { conseguia se concentrar na } \\
\text { atividade e se dispersava facilmente. } \\
\text { A atividade foi concluída, porém de } \\
\text { modo insatisfatório. Já no brincar } \\
\text { com o corpo, a criança se dispersou } \\
\text { durante a atividade, sendo necessário } \\
\text { retomar sua atenção o tempo } \\
\text { todo. Quando se concentrava na } \\
\text { atividade, realizava-a com sucesso, } \\
\text { identificando as partes do corpo. }\end{array}$} \\
\hline & $\begin{array}{l}\text { Brincando } \\
\text { com o corpo }\end{array}$ & $\begin{array}{l}\text { Estimular o esquema corporal e a } \\
\text { brincadeira decorreu de acordo com } \\
\text { comandos verbais. Toda vez que se } \\
\text { jogava a bola, a participante deveria } \\
\text { prestar atenção no comando antes de } \\
\text { realizar o movimento, por exemplo: } \\
\text { pegue a bola com as duas mãos, } \\
\text { pegue a bola com uma mão, chute a } \\
\text { bola com o pé esquerdo, pegue a bola } \\
\text { e coloque na cabeça. }\end{array}$ & \\
\hline Segundo & $\begin{array}{l}\text { Desenho do } \\
\text { corpo humano }\end{array}$ & $\begin{array}{l}\text { Estimular o esquema corporal. } \\
\text { A atividade constituiu em um } \\
\text { desenho do corpo humano, no } \\
\text { qual a participante deveria olhar e } \\
\text { reconhecer quais partes do corpo } \\
\text { estavam faltando e em seguidas } \\
\text { colocá-las no lugar adequado. }\end{array}$ & $\begin{array}{l}\text { A criança se dispersou durante a } \\
\text { atividade, necessitou de muitas dicas } \\
\text { verbais e auxílio da pesquisadora para } \\
\text { desenhar as partes do corpo. Teve } \\
\text { muita dificuldade em achar a parte do } \\
\text { corpo que estava faltando no desenho } \\
\text { e de colocá-la depois no lugar certo. } \\
\text { Concluiu a atividade, mas de modo } \\
\text { insatisfatório. }\end{array}$ \\
\hline
\end{tabular}


Tabela 1. Continuação...

\begin{tabular}{|c|c|c|c|}
\hline Atendimento & Brincadeiras & Objetivos e Procedimentos & Desempenho \\
\hline Terceiro & $\begin{array}{l}\text { Colagem de } \\
\text { objetos }\end{array}$ & $\begin{array}{l}\text { Estimular a organização temporal } \\
\text { e espacial. Consistiu em algumas } \\
\text { figuras dispostas para a participante e } \\
\text { ela deveria reconhecer quais objetos } \\
\text { eram mais adequados para enfeitar } \\
\text { cada figura e os lugares adequados } \\
\text { que eles deveriam ficar. Alguns } \\
\text { comandos verbais eram dados por } \\
\text { exemplo: cole o sol em cima da casa, } \\
\text { cole o coelho embaixo da árvore, } \\
\text { antes de dormir você coloca que } \\
\text { roupa, entre outros comandos. }\end{array}$ & $\begin{array}{l}\text { A criança se dispersou com os } \\
\text { estímulos externos, porém conseguiu } \\
\text { permanecer sentada por mais tempo. } \\
\text { Necessitou de auxílio verbal e dicas } \\
\text { visuais para realizar a atividade, e } \\
\text { teve muita dificuldade em diferenciar } \\
\text { e memorizar, em cima, em baixo. } \\
\text { Concluiu a atividade, porém de modo } \\
\text { insatisfatório. }\end{array}$ \\
\hline Quarto & Siga o mestre & $\begin{array}{l}\text { Estimular organização espacial, } \\
\text { temporal e o esquema corporal. Nessa } \\
\text { atividade, a participante deveria } \\
\text { esperar para ver quais eram as ações } \\
\text { da terapeuta e imitá-la, por exemplo: } \\
\text { colocar uma mão no nariz, levantar a } \\
\text { perna direita, colocar as duas mãos na } \\
\text { cabeça, entre outros comandos. }\end{array}$ & $\begin{array}{l}\text { Dicas visuais e comandos verbais } \\
\text { foram dados o tempo todo, porém a } \\
\text { criança estava dispersa e agitada, não } \\
\text { prestando atenção. Quando solicitada, } \\
\text { imitava gestos quaisquer e já se } \\
\text { focava em outra coisa. A atividade } \\
\text { não foi concluída. }\end{array}$ \\
\hline
\end{tabular}

Estimular organização espacial, temporal e esquema corporal. Nessa brincadeira, o primeiro passo foi disponibilizar uma casinha de boneca, na qual deveriam ser colocados os móveis nos lugares adequados, porém era necessário esperar os comandos

Quinto Brincadeira da da terapeuta, por exemplo: aponte casinha onde fica a sala, qual móvel fica na sala, em que local você dorme, onde são feitas as refeições, e assim por diante. O segundo passo foi brincar com a boneca na casa, sendo requerido em alguns momentos da brincadeira reconhecer as partes do corpo da boneca.

Estimular esquema corporal. Nessa atividade, a participante ficava $\begin{array}{ccc}\text { Reflexo no } & \text { de frente para o espelho, olhando } \\ \text { espelho reconhecendo as partes do seu }\end{array}$ próprio corpo e de acordo com os comandos da terapeuta, ela mostrava o que estava sendo pedido.

Estimular a organização espacial e temporal. Essa atividade constituiu na leitura de uma história e a

Sétimo Reprodução de história. participante deveria recontá-la e fazer um desenho relacionado à história.

Estimular o esquema corporal. Nessa atividade, o desenho de um corpo humano foi reproduzido no espelho

Oitavo

Pintura no com tinta e a participante deveria espelho. olhar para o desenho e completar as partes do corpo. O espelho auxiliou para que ela pudesse olhar para seu próprio corpo também.
Atenção e concentração da criança estavam melhores, conseguindo prestar atenção nos comandos e se envolver na brincadeira. Com comandos verbais e menos auxílio, conseguiu realizar com mais satisfação a atividade, discriminando posições como em cima, em baixo, tempo, ordem etc.

\section{A criança manteve-se mais} concentrada na atividade, tendo dificuldade na lateralidade em alguns momentos, porém com comandos verbais e dicas visuais a atividade foi concluída com sucesso e de modo satisfatório.

\section{A criança ficou atenta à história} e, com auxílio verbal, recontou e desenhou a história contada de modo satisfatório.

Por causa da tinta, a criança se mostrou agitada mas manteve atenção nos comandos verbais para realização da atividade, e mesmo tendo dificuldade em algumas partes do corpo, conseguiu realizar a atividade. 
com os responsáveis. Foram mostradas todas as brincadeiras realizadas durante os atendimentos e relatado o desempenho da participante. Em seguida, foi explicado sobre os gráficos elaborados com base nos resultados e sobre as mudanças obtidas em relação às intervençôes.

\subsection{Procedimentos para análise de dados}

A EDM determina pontuaçóes para cada teste e prova motora que a compóe, de acordo com o desempenho exigido para a realizaçáo de cada tarefa. Por meio do procedimento aritmético, definido pela EDM, para pontuar os resultados dos testes individuais, produz-se um perfil motor de cada participante. Esses resultados individuais, reproduzidos graficamente quando comparados com a população normativa, indicam os sujeitos que não estão com o desenvolvimento psicomotor adequado para sua idade (ROSA NETO, 2002).

Como forma de realizar uma análise comparativa entre escores pré e pós-intervenção, foram adotadas as concepções e os critérios formulados pelo Método Jacobson e Truax (Método JT) (JACOBSON; TRUAX, 1991).

Esse método foi proposto para demonstrar a efetividade de uma intervenção, reunindo evidências empíricas pertinentes a sua validade interna e externa. O Método JT (JACOBSON; TRUAX, 1991) implica na realizaçáo de dois processos complementares, o cálculo do Índice de Mudança Confiável (IMC) e de Significância Clínica (SC). O IMC serve para determinar se as mudanças pré e pós-intervenção podem ser atribuídas à intervenção ou se devem a erros de medida. Atua como um indicador de erro da medida obtida na avaliação do cliente que irá ser comparado a uma distribuiçáo teórica de erros de medida do instrumento. Para isso, os autores desenvolveram uma fórmula específica baseada na diferença entre pré e pós-teste dividida pelo erro padrão da diferença. A SC permite verificar se as mudanças atingidas ocorreram em uma extensão que as caracterize como clinicamente relevante (JACOBSON; TRUAX, 1991).

Ao aplicar essa métrica na amostra dos participantes de um programa de intervenção, pode-se determinar a porcentagem de indivíduos que melhoraram com a intervenção mas não se recuperaram, o percentual de indivíduos que se recuperaram e o percentual de indivíduos que permaneceram inalterados ou que pioraram durante o tratamento. Esses percentuais descritivos podem ser comparados entre os grupos por meio de análises de tabelas de contingência para determinar se as diferenças observadas entre os grupos são estatisticamente significativas, ou podem simplesmente serem usadas de forma descritiva para aumentar o padrão das comparaçóes entre grupos baseadas em diferenças. De qualquer forma, as proporçôes fornecem informações valiosas sobre a variabilidade do resultado dentro de cada condiçáo de tratamento e por isso determina a importância prática da intervenção (JACOBSON et al., 1999; VILLA; AGUIAR; DEL PRETTE, 2012).

\section{Resultados}

As aquisiçôes esquema corporal, organização espacial e organização temporal foram avaliadas com a EDM e estimuladas com as brincadeiras do plano de intervenção.

Pode-se observar que no início dos atendimentos, a criança teve muita dificuldade em realizar as brincadeiras das primeiras sessóes, perdia o foco e atenção rapidamente, desistia com facilidade, tinha dificuldade em entender os comandos dados e não se concentrava nas atividades. Foi necessário o auxílio da pesquisadora para que a participante conseguisse se nortear durante as brincadeiras e finalizá-las com sucesso. Apenas a brincadeira "Siga o mestre" não pôde ser realizada, pois a criança náo se concentrou nos comandos.

A partir do $5^{\circ}$ atendimento, notou-se uma melhora na atenção e concentraçáo da criança durante as brincadeiras, conseguindo realizá-las com mais autonomia. A partir desse atendimento, a conclusão das etapas das brincadeiras começou a ser mais satisfatória. Na Tabela 1 segue a descrição das brincadeiras e o desempenho da participante.

As avaliaçôes das aquisiçôes pré e pós teste foram analisadas pelo Método JT, que produziu gráficos de dispersão que apresentam as mudanças confiáveis e clinicamente significativas ocorridas.

Em relação ao esquema corporal, o resultado da análise entre pré-teste e pós-teste 1 indica que a participante (S1) obteve mudança confiável, ou seja, que esta está relacionada com a intervenção e não se deve a um erro de medida.

Já a significância clínica, ou seja, se houve mudança de status clínico, observa-se que a participante estava na pré-intervenção na população disfuncional e no pós-teste 1 permaneceu nesta população, ou seja, as mudanças ocorridas não a fizeram sair de uma população disfuncional (população clínica) para uma população com um escore normativo (população 


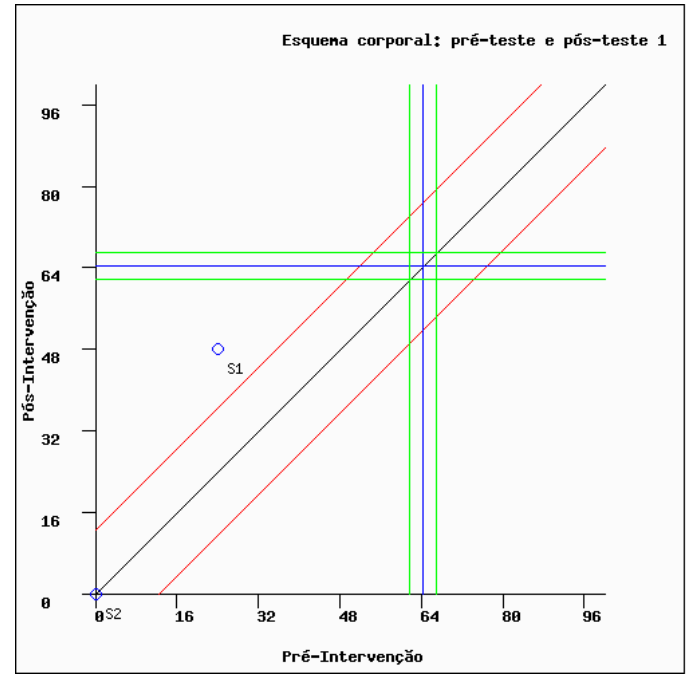

Figura 1. Esquema Corporal: pré-teste e pós-teste 1.

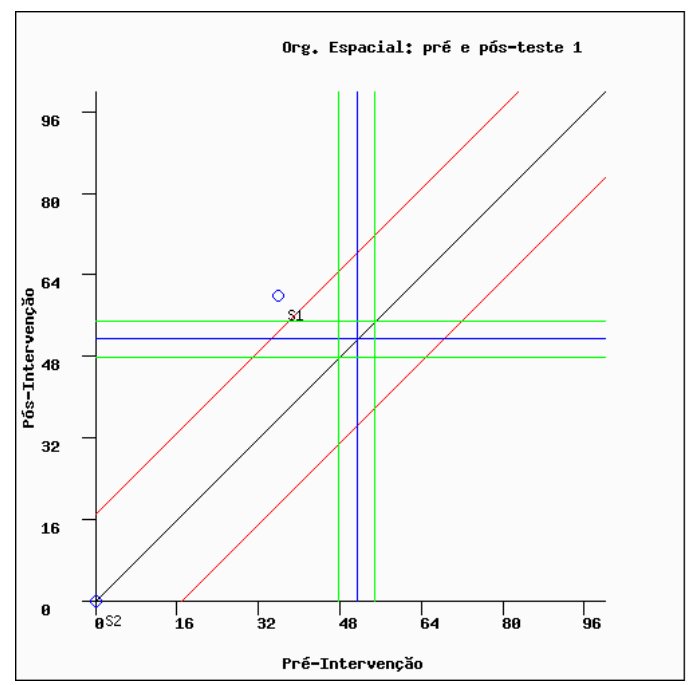

Figura 2. Organização espacial: pré-teste e pós-teste 1.

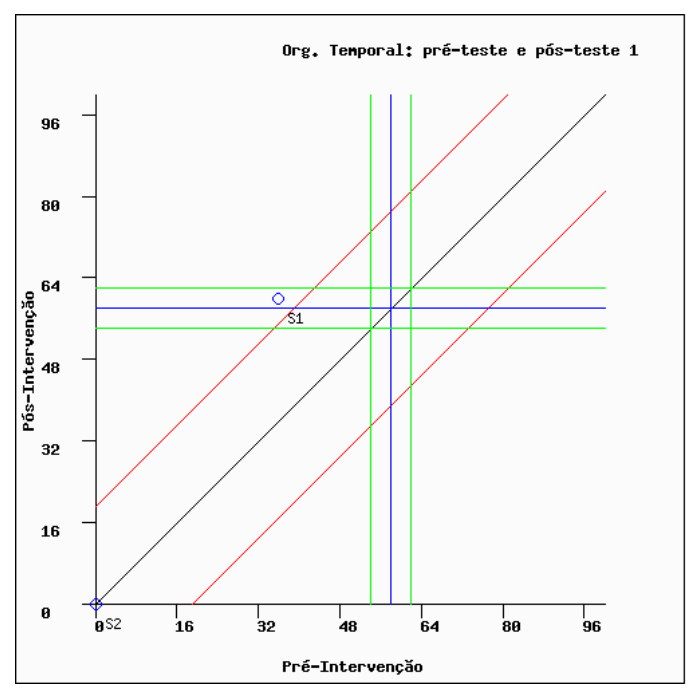

Figura 3. Organização temporal: pré-teste e pós-teste 1. náo clínica). A seguir, a Figura 1 apresenta estas informaçóes.

No item organização espacial, o resultado da análise entre pré-teste e pós-teste 1 indica que a participante (S1) obteve mudança confiável, ou seja, a mudança está relacionada com a intervenção e não se deve a um erro de medida.

A significância clínica, ou seja, se houve mudança de status clínico, aponta que a participante se apresentava na pré-intervenção na população disfuncional e no pós-teste 1 passou para a população funcional, ou seja, teve mudanças significativas, a ponto de sair de uma população disfuncional (população clínica) para uma populaçáo com um escore normativo (população náo clínica). Estes dados são apresentados na Figura 2.

Na organização temporal, o resultado da análise entre a avaliação entre pré-teste e pós-teste 1 indica que a participante (S1) também obteve mudança confiável, logo esta também está relacionada com a intervenção e não se deve a um erro de medida.

Em relação à significância clínica, se houve mudança de status clínico, tem-se que a participante obteve alteraçóes, mas por se encontrar na faixa de incerteza (ao redor da bissetriz), não é possível afirmar nada sobre esta, pois pode ser devida a erros de medida. A Figura 3 ilustra estes resultados.

\section{Discussão}

Os resultados obtidos demonstram que ocorreram mudanças positivas confiáveis nos itens psicomotores que passaram por estimulaçáo por meio de brincadeiras. Além disso, em um dos itens, a participante teve mudanças significativas a ponto de sair de uma população disfuncional para uma população com um escore normativo. A literatura corrobora este dado, apontando que o brincar tem sido utilizado como um recurso por terapeutas ocupacionais, ocasionando em efeitos positivos sobre o desenvolvimento infantil (SILVA; PONTES, 2013; SOUZA; MARINO, 2013). O estudo de Maronesi et al. (2015) avaliou o impacto de uma intervenção por meio de atividades lúdicas junto a uma criança com atraso no desenvolvimento psicomotor, e os resultados demonstraram mudanças positivas confiáveis nos itens psicomotores. No estudo de Souza e Marino (2013) que utilizou o brincar como estratégia de intervenção, verificou-se o quanto a atuação da terapia ocupacional foi benéfica e significativa na vida da criança, no sentido de maximizar o desempenho ocupacional satisfatório, contribuindo para uma melhora na qualidade de vida, independência e participação efetiva na atividade. 
Uma gama diversificada de profissionais de saúde tem as habilidades psicomotoras como foco na sua prática professional e adotam diferentes modelos para fundamentar as respectivas intervenções (NICHOLLS et al., 2016).

Neste sentido, os resultados aqui apresentados favorecem o reconhecimento da ação da terapia ocupacional enquanto um dos profissionais que compóe a equipe multidisciplinar voltada à intervenção de crianças com atrasos no desenvolvimento psicomotor. Desta forma, o terapeuta ocupacional possui funçôes específicas, como as realizadas nesta pesquisa, por exemplo, a aplicação de instrumento de avaliação padronizado e a elaboração de uma intervenção voltada às necessidades destas crianças (FIGUEIREDO; EMMEL; VILLA, 2015). Assim, hipotetiza-se que um prolongamento das intervençóes poderia favorecer a mudança de status clínico nos itens esquema corporal e organização temporal, uma vez que nos primeiros atendimentos à criança apresentou muita dificuldade em realizar as brincadeiras, o que foi gradativamente se modificando no transcorrer da concretização das intervençóes.

Na mesma medida, Beresford, Queiroz e Nogueira (2002) e Alves e Bianchin (2010), ao utilizarem um programa de intervençáo para estimular a atividade psicomotora, detectaram que ao mesmo tempo foram incrementados a concentração, a atenção, o raciocínio e a inteligência. Tal fato também pode ser observado na participante deste estudo, que nos atendimentos iniciais apresentou baixa atenção, concentração e dificuldades na realizaçáo das brincadeiras, mas paulatinamente obteve uma mudança nestes itens e uma respectiva melhora no desempenho das diferentes atividades que compunham o brincar terapêutico.

No presente estudo foi observado que, a partir da quinta brincadeira realizada, a criança manteve atenção e concentração na atividade por mais tempo, prestou atenção nos comandos dados pela pesquisadora, não foi preciso a repetiçáo de muitos conceitos, com auxílio verbal percebia os erros cometidos e corrigia-os, finalizando a atividade com sucesso.

O atraso no esquema corporal, na orientação espacial e temporal apresentados inicialmente pela participante desta pesquisa também foram detectados em outros estudos que avaliaram o desenvolvimento psicomotor de crianças e que indicaram que a avaliação e detectação se fazem de fundamental importância para a elaboração de intervenções que vão ao encontro das reais necessidades da clientela (FIGUEIREDO; EMMEL; VILLA, 2015; ROSA NETO et al., 2011; MEDINA; ROSA; MARQUES,
2006; CAETANO; SILVEIRA; GOBBI, 2005; BERESFORD; QUEIROZ; NOGUEIRA, 2002).

Segundo o estudo de Rosa Neto et al. (2011), comumente o esquema corporal está entre as principais áreas que apresentam maior déficit em relação ao esperado para a idade da criança.

Os resultados do estudo de Caetano, Silveira e Gobbi (2005) indicam que as capacidades que envolvem o esquema corporal das crianças investigadas desenvolveram-se por volta de quatro a cinco anos de idade e permaneceram nesse mesmo nível até o seis ou sete anos de idade. Desta forma, infere-se que a intervenção realizada nesta pesquisa favoreceu a melhora confiável e que a criança está em processo de desenvolvimento de seu esquema corporal, assim como da organizaçáo espacial e temporal, necessitando de novas intervençóes e estímulos, pois a literatura aponta que a constituição do esquema corporal é fundamental para o desenvolvimento da criança, constituindo-se uma referência para as diversas possibilidades de ação, implicando, inclusive, no desenvolvimento da organizaçáo espaço-temporal (ROSA NETO, 2002; ROSA NETO et al., 2007; MEDINA-PAPST; MARQUES, 2010).

No estudo de Pôrto e Ibiapina (2010), que analisou o desenvolvimento do esquema corporal de uma criança com Síndrome de Down mediante intervençóes em ambiente aquático como cenário terapêutico ocupacional, observaram uma evolução no desenvolvimento das habilidades relacionadas ao esquema corporal e, concomitantemente, verificaram uma participação mais ativa e autônoma nas atividades da vida diária.

Já a pesquisa de Figueiredo, Emmel e Villa (2015) refere que, mediante a ocorrência de intervençōes, as crianças que obtiveram melhoras no esquema corporal e na organização especial foram as mesmas que obtiveram alteraçóes positivas no desempenho da leitura, na medida em que as noçóes de corpo, tempo e espaço são essenciais no processo de aprendizagem escolar da leitura e da linguagem escrita.

Em contrapartida, no trabalho de Park, Jeong e Bornman (2011), que teve como objetivo descrever a eficácia de uma intervenção psicomotora em crianças com atrasos no desenvolvimento, verificaram que, em primeiro lugar, houve eficácia na melhora do equilíbrio, controle postural e na coordenação motora e, secundariamente, ocorreram incrementos no esquema corporal e na orientaçáo espacial. Tais estudos reforçam o pressuposto de que, quando tais componentes psicomotores estáo em pleno funcionamento, impactam no desenvolvimento integral da criança, permitindo-lhe atuar de forma 
eficiente no aprendizado de tarefas de diversas áreas (VIEIRA, 2004; ROSA NETO et al., 2011). Além disso, denotam que as habilidades psicomotoras são primeiramente estimuladas pelos profissionais para consequentemente serem aprimoradas e aprendidas pelos sujeitos alvo das intervençóes. A literatura contemporânea sobre aprendizagem motora e cognição contém quadros instrucionais que favorecem a fundamentaçáo das práticas, assim como propicia que as mesmas ocorram de forma mais eficaz e efetiva (NICHOLLS et al., 2016).

\section{Conclusão}

Neste estudo, avaliou-se o impacto de uma intervençáo para uma criança com atraso no desenvolvimento psicomotor. Os resultados demonstraram mudanças positivas e confiáveis nos itens esquema corporal, organização espacial e temporal, ou seja, estas mudanças podem ser atribuídas à intervenção. Em relação à mudança de status clínico, apenas no item organização espacial as mudanças ocorridas deslocaram a criança da populaçáo disfuncional para a funcional, mas nos itens esquema corporal e organizaçáo temporal a criança ainda apresentou no pós-teste escore abaixo do normativo para a sua faixa etária.

Durante a infância, muitas crianças podem apresentar alteraçôes no curso do seu desenvolvimento em função de um meio pobre em estímulos ou em decorrência de alguma patologia associada, ocasionando déficits nas habilidades necessárias para a aprendizagem. As aquisiçóes das habilidades motoras estáo vinculadas integralmente ao desenvolvimento da percepção do corpo, espaço e tempo, sendo esses três elementos indissociáveis. Desta forma, os resultados confirmam um efeito positivo do programa de intervençáo terapêutico proposto, sendo que as brincadeiras, elaboradas e realizadas com a participante do estudo, favoreceram o aprimoramento dos itens acima citados.

Com isso, o presente estudo reforça a relevância de programas de estimulação que envolvam o brincar e brincadeiras para o desenvolvimento das habilidades psicomotoras com atrasos. Uma vez que o brincar é um comportamento inerente à infância, propicia o desenvolvimento, aprimoramento e/ou refinamento de diferentes habilidades, justifica-se a sua importância enquanto recurso terapêutico ocupacional.

Ressalta-se também a relevância da ação do terapeuta ocupacional enquanto um dos profissionais da equipe multidisciplinar que atua com crianças com atrasos psicomotores. Este profissional atende às necessidades de intervenção de crianças com atrasos psicomotores na medida em que são habilitados nas avaliaçôes e elaboração de programas de reabilitação que vão ao encontro da necessidade de desenvolvimento e/ou aprimoramento do esquema corporal, organização espacial e temporal.

O estudo, por envolver uma única criança, apresenta limitaçóes, e os resultados devem ser considerados sob estas perspectivas. Além disso, há de se considerar que a criança permaneceu realizando fonoaudiologia e que o próprio processo de desenvolvimento natural dela pode ter influenciado nos resultados identificados.

Com isso, sugere-se a continuidade de investigaçóes sobre esta temática, na medida em que o desenvolvimento adequado do esquema corporal, da organização espacial e temporal tem repercussóes importantes no desempenho da criança em diferentes atividades do cotidiano e, consequentemente, em sua qualidade de vida. Desta forma, faz-se necessário a realização de novos estudos com maior número de participantes sobre o assunto em questáo para produção de novos dados e descobertas sobre a utilização do brincar em programas de intervenção no desenvolvimento de aquisiçóes psicomotoras.

\section{Referências}

ALVES, L.; BIANCHIN, M. A. O jogo como recurso de aprendizagem. Revista Psicopedagogia, São Paulo, v. 27, n. 83, p. 282-287, 2010.

BERESFORD, H.; QUEIROZ, M.; NOGUEIRA, A. B. Avaliação das relaçóes cognitivas e motoras na aquisição instrucional das habilidades para a aprendizagem da linguagem escrita. Revista Ensaio: avaliação e políticas públicas em educacional, Rio de Janeiro, v. 10, n. 37, p. 493-501, 2002.

CAETANO, M. J. D.; SILVEIRA, C. R. A.; GOBBI, L. T. B. Desenvolvimento motor de pré escolares no intervalo de 13 meses. Revista Brasileira de Cineantropometria e Desempenho Humano, Florianópolis, v. 7, n. 2, p. 5-13, 2005.

CASE-SMITH, J. Occupational therapy for children. Missouri: Elsevier Mosby, 2005.

CRUZ, D. M. C. Terapia Ocupacional com crianças portadoras de necessidades especiais: uma análise do origami como proposta de estimulação psicomotora. $\mathrm{Ca}$ dernos de Terapia Ocupacional da UFSCar, São Carlos, v. 10, n. 2, p. 119-128, 2002

CRUZ, D. M. C.; EMMEL, M. L. G. O brinquedo e o Brincar na estimulação da função manual de crianças pré-escolares com deficiência física. Cadernos de Terapia Ocupacional da UFSCar, São Carlos, v. 15, n. 1, p. 7-17, 2007. 
DE MEUR, A.; STAES, L. Psicomotricidade: educação e reeducação: níveis maternal e infantil. Sáo Paulo: Editora Manole, 1991.

FERNANDES, C. T.; DANTAS, P. M. S.; MOURÃO-CARVALHAL, M. I. Desempenho psicomotor de escolares com dificuldades de aprendizagem em cálculos. Revista Brasileira de Estudos Pedagógicos, Brasília, v. 95, n. 239, p. 112-138, 2014.

FIGUEIREDO, M. O.; EMMEL, M. L. G.; ROSÁRIO, P. Caracterização do desenvolvimento psicomotor de alunos com dificuldade de aprendizagem. In: CONGRESSO INTERNACIONAL GALEGO-PORTUGUÊS DE PSICOPEDAGOGIA, 12., 2013, Braga. Anais... Braga: Universidade do Minho, 2013. p. 53365350. Disponível em: <http://webs.ie.uminho.pt/xiigp/ at11.pdf > . Acesso em: 23 maio 2016.

FIGUEIREDO, M. O.; EMMEL, M. L. G.; VILLA, M. B. Terapia ocupacional e alunos com dificuldades de aprendizagem: análise de uma intervençáo nos aspectos psicomotores. Temas Sobre Desenvolvimento, São Paulo, v. 20, n. 110-111, p. 125-131, 2015.

FONSECA, F. R.; BELTRAME, T. S.; TKAC, C. M. Relação entre o nível de desenvolvimento motor e variáveis do contexto de desenvolvimento de crianças. Revista da Educação Física, Maringá, v. 19, n. 2, p. 183-194, 2008.

GALLAHUE, D. L. Educação Física desenvolvimentista. Cinergis, Santa Cruz do Sul, v. 1, n. 1, p. 7-17, 2000.

GALLAHUE, D. L.; OZMUN, J. C.; GOODWAY, J. D. Compreendendo o desenvolvimento motor: bebês, crianças, adolescentes e adultos. Porto Alegre: AMGA, 2013.

GIARDINETTO, A. R. D. S. B. et al. A importância da atuação da terapia ocupacional com a população hospitalizada: A visão dos profissionais da área da saúde. $\mathrm{Ca}$ dernos de Terapia Ocupacional da UFSCar, São Carlos, v. 17, n. 1, p. 63-69, 2009.

GRIGOLATTO, T. et al. Intervençấo terapêutica ocupacional em CTI pediátrico: um estudo de caso. Cadernos de Terapia Ocupacional da UFSCar, São Carlos, v. 16, n. 1, p. 37-46, 2008.

HAYWOOD, K. M.; GETCHELL, N. Desenvolvimento motor ao longo da vida. Porto Alegre: Artmed, 2004.

JACOBSON, N. S. et al. Methods for defining and determining the clinical significance of treatment effects: description, application and alternatives. Journal of Consulting and Clinical Psychology, Washington, v. 67, n. 3, p. 300-307, 1999.

JACOBSON, N. S.; TRUAX, P. Clinical significance: a statistical approach to defining meaningful change in psychotherapy research. Journal of Consulting and Clinical Psychology, Washington, v. 59, n. 1, p. 12-19, 1991.

KENNY, D. A. A quasi-experimental approach to assessing treatment effects in the nonequivalent control group design. Psychological Bulletin, California, v. 82, n. 3, p. 345-362, 1975.

KNOX, S. Avaliação lúdica de pré-escolares: a escala Knox. In: PARHAM, L. D.; FAZIO, L. S. A recreação na terapia ocupacional pediátrica. São Paulo: Santos, 2002. p. 2-22.

MARONESI, L. C. et al. Análise de uma intervenção dirigida ao desenvolvimento da coordenaçáo motora fina, global e do equilíbrio. Cadernos de Terapia Ocupacional da UFSCar, São Carlos, v. 23, n. 2, p. 273-284, 2015.

MEDINA, J.; ROSA, G. K. B.; MARQUES, I. Desenvolvimento da organizaçáo temporal de crianças com dificuldades de aprendizagem. Revista da Educação Física, Maringá, v. 17, n. 1, p. 107-116, 2006.

MEDINA-PAPST, J.; MARQUES, I. Avaliaçăo do desenvolvimento motor de crianças com dificuldade de aprendizado. Revista Brasileira de Cineantropometria e Desempenho Humano, Florianópolis, v. 12, n. 1, p. 3642, 2010.

NICOLA, M. Psicomotricidade: manual básico. Rio de Janeiro: Revinter, 2004.

NICHOLLS, D. et al. Teaching psychomotor skills in the twenty-first century: revisiting and reviewing instructional approaches through the lens of contemporary literature. Medical Teacher, London, v. 38, n. 10, p. 1056-1063, 2016.

NUNES, S. B. F. et al. Retratos do cotidiano de meninos de cinco e seis anos: a atividade de brincar. Cadernos de Terapia Ocupacional da UFSCar, São Carlos, v. 21, n. 2, p. 275-287, 2013.

OLIVEIRA, A. F. S.; SOUZA, J. M. A importância da psicomotricidade no processo de aprendizagem infantil. Revista Fiar: Núcleo de Pesquisa e Extensão, Ariquemes, v. 2, n. 1, p. 125-146, 2013.

OLIVEIRA, G. C. Psicomotricidade: educação e reeducação num enfoque psicopedagógico. Petrópolis: Editora Vozes, 2002.

OLIVEIRA, I. C. C.; FRANCISCHINI, R. Direito de brincar: as (im)possibilidades no contexto de trabalho infantil produtivo. Psico-USF, Itatiba, v. 14, n. 1, p. 5970, 2009 .

PARK, W. H.; JEONG, Y. S.; BORNMAN, J. The effect of psycho-motor play on motor and body perception competence for young children with developmental. South African Journal of Occupational Therapy, Pretoria, v. 41, n. 1, p. 1-6, 2011.

PINTO, M. Vigilância do desenvolvimento psicomotor e sinais de alerta. Revista Portuguesa Clinica Geral, Lisboa, v. 25, n. 6, p. 677-687, 2009.

PÔRTO, C. M. V.; IBIAPINA, S. R. Ambiente aquático como cenário terapêutico ocupacional para o desenvolvimento do esquema corporal em síndrome de down. Revista Brasileira de Promoção da Saúde, Fortaleza, v. 23, n. 4, p. 389-394, 2010. 
ROSA NETO, F. Manual de avaliação motora. Porto Alegre: ArtMed, 2002.

ROSA NETO, F. et al. Desenvolvimento motor de crianças com indicadores de dificuldades na aprendizagem escolar. Revista Brasileira de Ciência e Movimento, Taguatinga, v. 15, n. 1, p. 45-51, 2007.

ROSA NETO, F. et al. A importância da avaliação motora em escolares: análise da confiabilidade da escala do desenvolvimento motor. Revista Brasileira de Cineantropometria e Desempenho Humano, Florianópolis, v. 16, n. 1, p. 422-427, 2010.

ROSA NETO, F. et al. O esquema corporal de crianças com dificuldade de aprendizagem. Revista Semestral da Associação Brasileira de Psicologia Escolar e Educacional, Uberlândia, v. 15, n. 1, p. 15-22, 2011.

SCALHA, T. B. et al. A importância do brincar no desenvolvimento psicomotor: relato de experiência. Revista de Psicologia da UNESP, Assis, v. 9, n. 2, p. 79-92, 2010.

SHANDISH, W. R. Quasi-experimental designs. In: SMELSER, N. J.; BALTES, P. B. International Encyclopedia of the Social \& Behavioral Sciences. Pergamon: Oxford, 2001. p. 12655-12659.

SILVA, C. C. B.; PONTES, F. V. A utilização do brincar nas práticas de terapeutas. Revista de Terapia Ocupacional da Universidade de São Paulo, São Paulo, v. 24, n. 3, p. 226-232, 2013.

SIMON, C. J. Uso de la actividad y análisis de la actividad. In: HOPKINS, H. L.; SMITH, H. D. Willard Spackman: Terapia Ocupacional. Madri: Panamericana, 2001. p. 281-29.

SOUZA, A. C.; MARINO, M. S. F. Atuação da Terapia Ocupacional com criança com atraso no desenvolvimento neuropsicomotor. Cadernos de Terapia Ocupacional da UFSCar, São Carlos, v. 21, n. 1, p. 149-153, 2013.

VASCONCELLOS, M. J. E. Pensamento sistêmico: o novo paradigma da ciência. Campinas: Papirus, 2002.

VIEIRA, L. F. Santos et al. Análise da aprendizagem perceptivo-motora de crianças de 7 e 8 anos da rede de ensino público de Maringá - PR. Revista da Educação Física, Maringá, v. 15, n. 2, p. 39-48, 2004.

VILLA, M. B.; AGUIAR, A. A. R.; DEL PRETTE, Z. A. P. Intervençōes baseadas em evidências: aplicaçôes do método JT. São Carlos: EDUFSCar, 2012.

WILLRICH, A.; AZEVEDO, C. C. F.; FERNANDES, J. O. Desenvolvimento motor na infância: influência dos fatores de risco e programas de intervenção. Revista Neurociências, São Paulo, v. 17, n. 1, p. 51-56, 2009.

\section{Contribuição dos Autores}

Sara Domiciano Franco de Campos e Mirela de Oliveira Figueiredo foram responsáveis pela concepção e redação do texto e organização de fontes e das análises. Sheila Maria Mazer-Gonçalves, Elisandra dos Santos e Letícia Carrillo Maronesi foram responsáveis pela revisão do artigo. Todos os autores aprovaram a versão final do texto.

\section{Notas}

${ }^{1}$ Esta pesquisa foi aprovada pelo Comitê de Ética em Pesquisa CAAE-0014.0.457.000-11. 